\title{
Analgesic effects of calcitonin on radicular pain in male rats
}

This article was published in the following Dove Medical Press journal: Journal of Pain Research

\section{Yoshinori Terashima ${ }^{1,2}$ \\ Tsuneo Takebayashi ${ }^{3}$ \\ Shunsuke Jimbo' \\ Izaya Ogon' \\ Tatsuya Sato ${ }^{2}$ \\ Nobutoshi Ichise ${ }^{2}$ \\ Noritsugu Tohse ${ }^{2}$ \\ Toshihiko Yamashita'}

'Department of Orthopaedic Surgery, School of Medicine, Sapporo Medical University, Sapporo 060-006I, Japan; ${ }^{2}$ Department of Cellular Physiology and Signal Transduction, School of Medicine, Sapporo Medical University, Sapporo 060-006 I, Japan; '3Sapporo Maruyama Orthopaedic Hospital, Sapporo 060-0007, Japan
Correspondence: Yoshinori Terashima Department of Orthopaedic Surgery, School of Medicine, Sapporo Medical University, 16 West I South, Chuo-ku, Sapporo 060-006I, Japan

$\mathrm{Tel}+8|||6||2|||$

Fax +8111 6II 2111

Email y.terashima@sapmed.ac.jp
Purpose: Radicular pain is a frequently observed symptom of lumbar disk herniation or lumbar spinal canal stenosis. Achieving radicular pain relief is difficult. This type of pain may progress to chronic neuropathic pain. Calcitonin (elcatonin [eCT]) has been used mainly for hypercalcemia and pain associated with osteoporosis. The purpose of this study was to investigate analgesic effects of repeated eCT administration on radicular pain in male rats and changes in mRNAexpression levels of voltage-dependent sodium channels in the dorsal root ganglion (DRG).

Methods: Seventy male Sprague-Dawley rats were used. A right L5 hemilaminectomy and an L5-L6 partial facetectomy were performed to expose the right L5 nerve root. Under a microscope, the right L5 spinal nerve root was tightly ligated extradurally with 8-0 nylon suture proximally to the DRG to cause radicular pain in rats. Mechanical hyperalgesia, thermal hyperalgesia, and analgesic effects of eCT were compared among rats with radicular pain that received eCT, those that received the vehicle, and sham rats that received the vehicle. Real-time reverse-transcription PCR was performed to measure mRNA-expression levels of tetrodotoxin-sensitive $\left(\mathrm{Na}_{\mathrm{v}} 1.3\right.$ and $\left.\mathrm{Na}_{\mathrm{v}} 1.6\right)$ and tetrodotoxin-resistant $\left(\mathrm{Na}_{\mathrm{v}} 1.8\right.$ and $\left.\mathrm{Na}_{\mathrm{v}} 1.9\right)$ sodium channels in the DRG.

Results: Mechanical and thermal hyperalgesic reactions occurring in rats with radicular pain significantly improved on days 5 and 9 of eCT administration, respectively. In rats with radicular pain, mRNA-expression levels of $\mathrm{Na}_{\mathrm{v}} 1.3, \mathrm{Na}_{\mathrm{v}} 1.8$, and $\mathrm{Na}_{\mathrm{v}} 1.9$ increased. After repeated eCT administration, mRNA-expression levels of these sodium channels in rats with radicular pain improved to the same levels as in sham rats.

Conclusion: The present study demonstrated that repeated systemic eCT administration was effective for radicular pain. No serious side effects of eCT have been reported thus far. Therefore, calcitonin may be a preferred therapeutic option for patients with radicular pain or for those requiring long-term treatment.

Keywords: radiculopathy, hyperalgesia, lumbar disk herniation, lumbar spinal canal stenosis, sodium channel, elcatonin

\section{Introduction}

Radicular pain is a frequently observed symptom of lumbar disk herniation or lumbar spinal canal stenosis. It manifests as spontaneous pain and hyperalgesia generally located at the gluteal region, thigh, leg, and foot, and is believed to be caused by a series of changes in the sensory processing system, functional reorganization of sensory transmission, and development of neural plasticity in the peripheral and central nervous systems.

Radicular pain results from an injury at a site proximal to the dorsal root ganglion (DRG). To investigate pathophysiological changes involved in neuropathic pain, several 
types of animal models, such as chronic constriction injury (CCI), and spinal nerve ligation have been developed., ${ }^{1,2}$ The first reported animal model of radicular pain involved nerve-root ligation proximal to the DRG. ${ }^{3}$ This model was later modified, ${ }^{4}$ and it is characterized by long-lasting mechanical allodynia and thermal hyperalgesia, which mimic clinical symptoms of lumbar radicular pain that is observed in patients with lumbar spinal canal stenosis or lumbar disk herniation. We have previously reported studies using rat models of radicular pain in which injury to the nerve root increased the excitability and sodium-current amplitude of DRG. ${ }^{4}$ We presume that radicular pain is caused by changes in sodium-channel expression and current properties.

Voltage-gated sodium channels are key transmitters in cellular excitability and are essential for pain transmission. ${ }^{5}$ There are nine distinct voltage-gated sodium channel $\alpha$-subunits: $\mathrm{Na}_{\mathrm{v}} 1.1-1.9 . \mathrm{Na}_{\mathrm{v}} 1.1, \mathrm{Na}_{\mathrm{v}} 1.2, \mathrm{Na}_{\mathrm{v}} 1.3, \mathrm{Na}_{\mathrm{v}} 1.4$, $\mathrm{Na}_{\mathrm{v}} 1.6$, and $\mathrm{Na}_{\mathrm{v}} 1.7$ are sensitive to tetrodotoxin (TTX), whereas $\mathrm{Na}_{\mathrm{v}} 1.5, \mathrm{Na}_{\mathrm{v}} 1.8$, and $\mathrm{Na}_{\mathrm{v}} 1.9$ are resistant to TTX. Several isoforms, except $\mathrm{Na}_{\mathrm{v}} 1.4$ and $\mathrm{Na}_{\mathrm{v}} 1.5$, are expressed in the DRG. ${ }^{6} \mathrm{Na}_{\mathrm{v}} 1.1, \mathrm{Na}_{\mathrm{v}} 1.6, \mathrm{Na}_{\mathrm{v}} 1.7, \mathrm{Na}_{\mathrm{v}} 1.8$, and $\mathrm{Na}_{\mathrm{v}} 1.9$ are expressed in the adult DRG. ${ }^{7}$ The expression of $\mathrm{Na}_{\mathrm{v}} 1.3$ in the adult DRG contributes to abnormal sodium current, which has been implicated in various neuropathic pain disorders. ${ }^{8}$ We focused on changes in the TTX-sensitive $\left(\mathrm{Na}_{\mathrm{v}} 1.3\right.$ and $\left.\mathrm{Na}_{\mathrm{v}} 1.6\right)$ and the TTX-resistant $\left(\mathrm{Na}_{\mathrm{v}} 1.8\right.$ and $\left.\mathrm{Na}_{\mathrm{v}} 1.9\right)$ sodium channels in this study.

In the clinical setting, NSAIDs are commonly used to treat radicular pain; however, these have a poor analgesic effect in cases of chronic pain (long disease durations) or severe neural disorders. Furthermore, the use of NSAIDs is often limited by the onset of adverse effects, such as gastrointestinal disorders, which are frequently observed with their long-term administration. It is often difficult to achieve radicular pain relief, and in some cases it may progress to chronic neuropathic pain.

Calcitonin is a polypeptide comprising 32 amino acids that is secreted into the blood from parafollicular cells ( $\mathrm{C}$ cells) of the thyroid gland. It plays an important role in the regulation of bone metabolism as a hormone that suppresses bone resorption. Formulated eel calcitonin (elcatonin [eCT]) and salmon calcitonin have been used mainly to treat hypercalcemia and pain associated with osteoporosis..$^{9-12}$ eCT is more effective than NSAIDs in alleviating acute lumbar pain in the open-label randomized controlled trial. ${ }^{13}$ Calcitonin has also been used for pain associated with diabetic neuropathy and complex regional pain syndrome in a clinical setting. ${ }^{14,15}$
Furthermore, studies have reported on the efficacy of calcitonin in pain reduction without relevant side effects. ${ }^{10,13}$ There are no experimental and clinical studies about the effects of calcitonin on radicular pain. The analgesic effects of calcitonin have been confirmed in diseases other than osteoporosis; however, these analgesic effects may be mediated by a different mechanism from that underlying its action as an inhibitor of bone resorption. Calcitonin induces a slow outward current associated with a decrease in sodium conductance causing membrane hyperpolarization in identified neurons of aplysia. ${ }^{16}$ We expected calcitonin might have some effects on voltage-dependent sodium channels in the DRG. As such, the purpose of this study was to investigate the analgesic effects of repeated calcitonin administration on radicular pain in rats and to evaluate changes in mRNA-expression levels of voltage-dependent sodium channels in the DRG.

\section{Methods}

\section{Experimental animals}

A total of 70 male Sprague-Dawley rats weighing 150-170 g were used. All experimental procedures were approved by the Animal Care and Use Committee of the Sapporo Medical University School of Medicine, Sapporo, Japan. All efforts were made to minimize the animals' suffering and the number of animals used, and the experiments followed the ethical guidelines of the International Association for the Study of Pain. ${ }^{17}$ The method used to generate lumbar radicular pain in rats is briefly described. . $^{4,18}$

After rats had been anesthetized with inhalation of isoflurane, they were placed in the prone position. An incision was made posteromedially from L4 to $\mathrm{S} 1$ to expose the right L5-L6 facet joint. A right L5 hemilaminectomy and an L5-L6 partial facetectomy were performed to expose the right L5 spinal nerve root. Under a microscope, the right L5 spinal nerve root was tightly ligated extradurally with 8-0 nylon suture proximal to the DRG. Subcutaneous tissue and skin were then closed with 4-0 nylon sutures. In sham rats, L5-L6 intervertebral joints were exposed without constricting the spinal nerve root.

\section{Calcitonin administration}

eCT (20 U/kg; Asahi Kasei Pharma, Tokyo, Japan), a synthetic derivative of eel calcitonin, or the vehicle, was subcutaneously injected in the neck of rats with radicular pain five times per week for 3 weeks, starting on postoperative day 11. During the same period, sham rats were administered the vehicle. 


\section{Behavioral tests}

For this experiment, 27 rats were divided into three groups: 10 rats with radicular pain that received eCT $(\mathrm{RP}+\mathrm{eCT}$ group), 10 rats with radicular pain that received the vehicle ( $\mathrm{RP}+$ vehicle group), and 7 sham rats that received the vehicle (sham + vehicle group). Mechanical hypersensitivity and thermal hyperalgesia were compared between the three groups to investigate the analgesic effects of eCT.

\section{Mechanical hyperalgesia}

Rats were placed on a wire-mesh floor inside a Plexiglas chamber (IITC Life Science, Los Angeles, CA, USA) measuring $18 \times 25 \times 18 \mathrm{~cm}$. They were acclimatized to the environment for at least 20 minutes before the test. Mechanical stimuli were applied to the middle area between the footpads on the plantar surface of the right and left hind paws using a $3.8 \mathrm{~g}$ von Frey filament (Semmes-Weinstein; North Coast Medical, San Jose, CA, USA). This was repeated thrice at intervals of at least 10 minutes. Differences in the number of hind-paw escape responses between the affected and intact sides were the index for mechanical hyperalgesia, as in previous reports. ${ }^{418-20}$ This behavioral evaluation was conducted on the day before surgery and on postoperative days $4,7,10$, $13,15,19,22,26,29,33,36$, and 40 .

\section{Thermal hyperalgesia}

Rats were placed inside a Plexiglas chamber on a glass platform and allowed to acclimatize for at least 20 minutes before the test. A thermal stimulus was applied with a radiant heat source (Tail Flick Analgesia Meter; IITC Life Science) on the center of the hind paw, and the length of time (in seconds) of the hind paw's fleeing reaction was measured. This was alternately conducted on each foot five times at 5-minute intervals. The mean of differences between the affected and intact sides for the second to fifth stimulations was the index of thermal hyperalgesia and defined as the differential score. ${ }^{4,18-20}$ This procedure was performed after evaluating mechanical hyperalgesia.

\section{mRNA-expression levels of voltage- dependent sodium channels in DRG}

To measure mRNA-expression levels of voltage-dependent sodium channels in the DRG, 43 rats were divided into three groups: 14 rats with radicular pain that received eCT (RP + eCT group), 14 rats with radicular pain that received the vehicle ( $R P+$ vehicle group), and 15 sham rats that received the vehicle (sham + vehicle group). On the day after eCT or vehicle administration, for 3 weeks (30 days postsurgery), rats were anesthetized with ether. After verifying that they were in deep anesthesia, the right L5 DRG was harvested.

Real-time reverse-transcription (RT) PCR was performed to measure mRNA-expression levels of TTX-sensitive $\left(\mathrm{Na}_{\mathrm{v}} 1.3, \mathrm{Na}_{\mathrm{v}} 1.6\right)$ and TTX-resistant $\left(\mathrm{Na}_{\mathrm{v}} 1.8, \mathrm{Na}_{\mathrm{v}} 1.9\right)$ sodium channels in the DRG. ${ }^{21}$ The right L5 DRG was immersed in $0.5 \mathrm{~mL}$ RNAlater (Ambison, Austin, TX, USA) and stored at $-80^{\circ} \mathrm{C}$. RNA was extracted in a single step using Trizol (Thermo Fisher Scientific, Waltham, MA, USA) and chloroform. After centrifugation at 15,000 rpm for 15 minutes, the RNA-containing aqueous phase was precipitated in isopropanol. The RNA pellet was then washed once in $75 \%$ ethanol and resuspended in $100 \mu \mathrm{L}$ RNase-free water. Total RNA from each sample was extracted using RNeasy minicolumns with DNase I (Qiagen NV, Venlo, the Netherlands) to reduce the contamination of genomic DNA prior to RT-PCR

The primer and probe for $\mathrm{Na}_{\mathrm{v}} 1.3$ were designed according to the TaqMan protocol, and those for $\mathrm{Na}_{\mathrm{v}} 1.8$ and $\mathrm{Na}_{\mathrm{v}} 1.9$ were designed following the method by Sleeper et al. ${ }^{22}$ The software Primer Express (Thermo Fisher Scientific) was used, and the specificity was verified using BLAST. Commercial sets (Rn00570506_m1, TaqMan gene-expression assay; Thermo Fisher Scientific) for $\mathrm{Na}_{\mathrm{v}} 1.6$ and rodent GAPDH control reagents (VIC Probe, 4308313; Thermo Fisher Scientific) were used. With GADPH as the endogenous control, mRNAexpression levels of sodium channels were normalized to those of GAPDH and then compared among the three groups.

Target genes were amplified using specific primers for $\mathrm{Na}_{\mathrm{V}} 1.3$ (forward 5'-CCAATAACACGGGCATCGA-3', reverse 5'-CACCCCGCTGGTGGTT-3'; probe 5'-FAMATAAGCAAAGAGCTTAACTACCTT-3' [TaqMan MGB]), $\mathrm{Na}_{\mathrm{v}} 1.8$ (forward 5'-TGGTCAACTGCGTGTGCAT-3', reverse 5'-AATCAGAGCCTCGAAGGTGTAAA-3'; probe 5'-FAM-CCGAACTGATCTTCCAGAGAAAGTCGAGTACGT-TAMRA-3'), and $\mathrm{Na}_{\mathrm{v}} 1.9$ (forward 5'-TGCCCTACCCACCTCACAAC-3', reverse 5'-CCGGGCTAGTGAGCTGCTT-3'; probe 5'-FAMTICAGGCCGGTGACCTCCCTCC-TAMRA-3'). Primers for GAPDH and the others were used at final concentrations of 100 and $900 \mathrm{nM}$, respectively, whereas probes were used at final concentrations of 200 and $250 \mathrm{nM}$, respectively. Realtime RT-PCR was performed using TaqMan one-step RT-PCR reaction-mix reagent. Amplification was performed in a final volume of $50 \mu \mathrm{L}$ under conditions of 30 minutes at $48^{\circ} \mathrm{C}, 10$ minutes at $95^{\circ} \mathrm{C}$, and then 40 cycles of $95^{\circ} \mathrm{C}$ for 15 seconds each, followed by $60^{\circ} \mathrm{C}$ for 1 minute. To determine transcript levels, relative standard-curve methods were constructed using a serial dilution of RNA from each tissue sample. ${ }^{23,24}$ 


\section{Statistical analyses}

All numerical data are expressed as mean \pm SEM. Behavioral test data were analyzed with two-way repeated-measure ANOVA. Among- and between-group comparisons were done using Dunnett's test and unpaired Student's $t$-test, respectively. $P<0.05$ was considered statistically significant.

\section{Results}

\section{Evaluation of behavioral tests}

The time courses of withdrawal frequencies in the RP + $\mathrm{eCT}, \mathrm{RP}+$ vehicle, and sham + vehicle groups in response to mechanical stimuli using $3.8 \mathrm{~g}$ von Frey filament are shown in Figure 1A. Rats with radicular pain exhibited a significantly higher level of mechanical hyperalgesia from postoperative day 4 and thereafter than the sham rats $(P<0.05)$. Furthermore, mechanical hyperalgesia was gradually relieved by eCT administration, and a significant improvement was observed in the $\mathrm{RP}+\mathrm{eCT}$ group 5 days after starting eCT administration compared with the RP + vehicle group $(P<0.05)$. Although hyperalgesia improved during the repeated $\mathrm{eCT}$ administration, it recurred 7 days after completing the treatment.

The differential score for noxious thermal stimuli was significantly higher in rats with radicular pain than in sham rats at postoperative day 4 and thereafter $(P<0.05$, Figure 1B). Furthermore, although hyperalgesia to heat stimulation improved significantly on day 9 after starting eCT administration, thermal hyperalgesia recurred 7 days after completing the treatment.

\section{Change in mRNA-expression levels of voltage-dependent sodium channels in DRG}

The right L5 DRG was harvested on the day following eCT administration, or vehicle administration for 3 weeks (30 days postsurgery). Sodium-channel mRNA-expression levels were normalized to those of GAPDH and then compared among the $\mathrm{RP}+\mathrm{eCT}, \mathrm{RP}+$ vehicle, and sham + vehicle groups using relative values to the mean value of the sham group.

mRNA-expression levels of $\mathrm{Na}_{\mathrm{v}} 1.3$ for the sham + vehicle and RP + vehicle groups were $0.82 \pm 0.04$ and $1.19 \pm 0.09$, respectively; therefore, the expression increased significantly in the latter group $(P<0.05)$. In the $\mathrm{RP}+\mathrm{eCT}$ group, the expression level was $0.98 \pm 0.04$, indicating that expression levels of $\mathrm{Na}_{\mathrm{v}} 1.3$ improved to the same level as those of the sham group (Figure 2A). However, no significant differences were observed in expression levels of $\mathrm{Na}_{\mathrm{v}} 1.6$ among the sham + vehicle $(0.62 \pm 0.03), R P+$ vehicle $(0.71 \pm 0.06)$, or $\mathrm{RP}+\mathrm{eCT}(0.59 \pm 0.04$, Figure $2 \mathrm{~B})$ groups.

In contrast, mRNA-expression levels of $\mathrm{Na}_{\mathrm{v}} 1.8$ and $\mathrm{Na}_{\mathrm{v}} 1.9$ were $0.92 \pm 0.07$ and $0.92 \pm 0.08$ in the sham + vehicle group and $1.37 \pm 0.10$ and $1.26 \pm 0.10$ in the RP + vehicle group, respectively; therefore, levels increased significantly in the latter group $(P<0.05)$. Furthermore, levels were $0.94 \pm 0.05$ and $0.99 \pm 0.06$ in the $\mathrm{RP}+\mathrm{eCT}$ group, respectively, indicating that mRNA-expression levels of $\mathrm{Na}_{\mathrm{v}} 1.8$ and $\mathrm{Na}_{\mathrm{v}} 1.9$ improved to the same level as those in the sham group (Figure 2C and D).

\section{Discussion}

Mechanical and thermal hyperalgesic reactions occurring in rats with radicular pain had improved significantly by days 5 and 9 of calcitonin administration, respectively, demonstrating that repeated systemic administration of calcitonin was effective in reducing radicular pain, mechanical hyperalgesia (allodynia), and thermal hyperalgesia. Although few preclinical experiments have demonstrated the analgesic effects of calcitonin, the efficacy of calcitonin in a model of acute pain in rats has been reported. ${ }^{25}$ Prior to the injection of formalin into the footpads of rats, these were treated with repeated subcutaneous injections of calcitonin ( $4 \mathrm{U} / \mathrm{kg} /$ day) for 7 days. As a result, the intervention suppressed hyperalgesia in rats with acute pain. Aoki et $\mathrm{a}^{26}$ reported that calcitonin $(20 \mathrm{U} / \mathrm{kg} /$ day) almost completely reversed the effects of both cold and mechanical allodynia induced by oxaliplatin and paclitaxel. Ovariectomized rats with hyperalgesia improved after subcutaneous calcitonin administration ( $20 \mathrm{U} / \mathrm{kg} /$ day) for 3 weeks in a postmenopausal osteoporosis and chronic pain model. ${ }^{27}$ Although calcitonin disappears within 2 hours of injection into human and rat plasma, subsequent injection of calcitonin gradually enhances antihyperalgesic effects. ${ }^{28}$ These effects are maintained for several days after cessation of calcitonin administration. ${ }^{21,26}$ Ito et $\mathrm{al}^{21}$ found dose-dependent effects of eCT $(1.5,15$, and $30 \mathrm{U} / \mathrm{kg} /$ day $)$ on both mechanical and thermal hyperalgesia in CCI rats. The present study results demonstrated that subcutaneous administration of eCT (20 $\mathrm{IU} / \mathrm{kg} /$ day, five times a week) for 3 weeks produced full relief of radicular pain in rats. Hyperalgesic reactions recurred 7 days after the completion of calcitonin administration. This finding suggests that calcitonin inhibits pain via direct antinociception on damaged nerves. Further study is needed to investigate the smallest single-dose quantity of eCT and the ideal number of administration times for suppressing radicular pain in rats. Calcitonin injected systemically binds to calcitonin receptors at blood-brain barrier-free regions, 


\section{A}

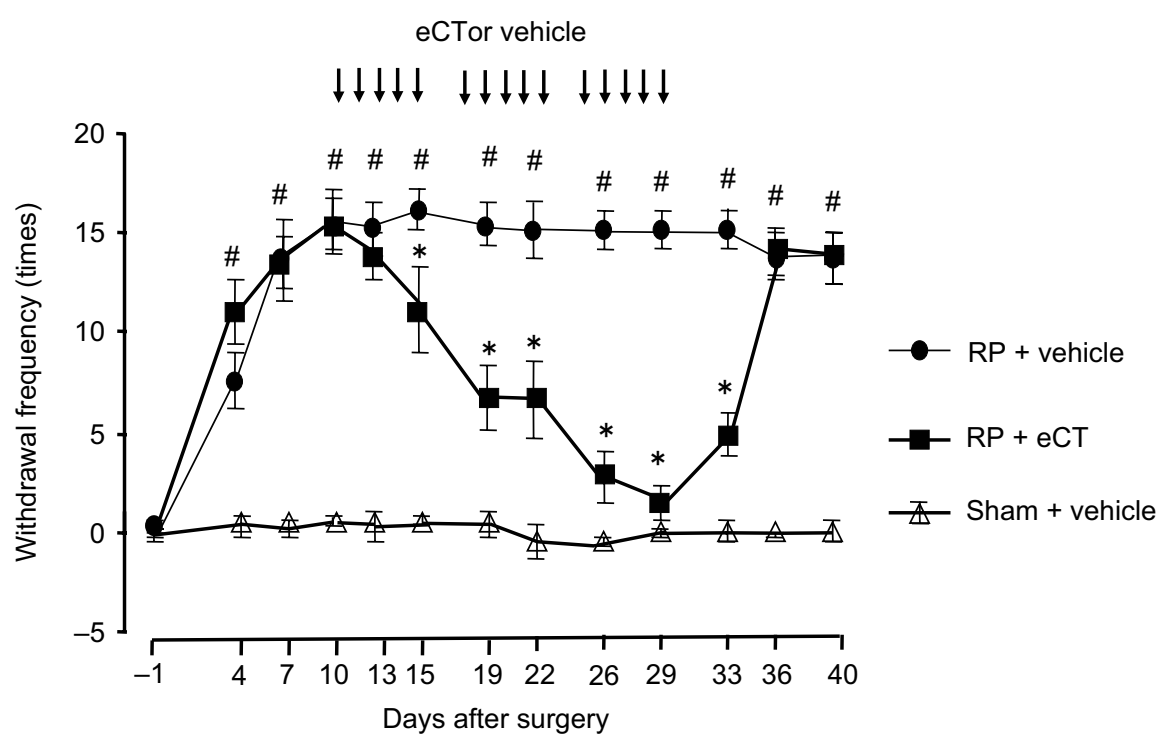

B

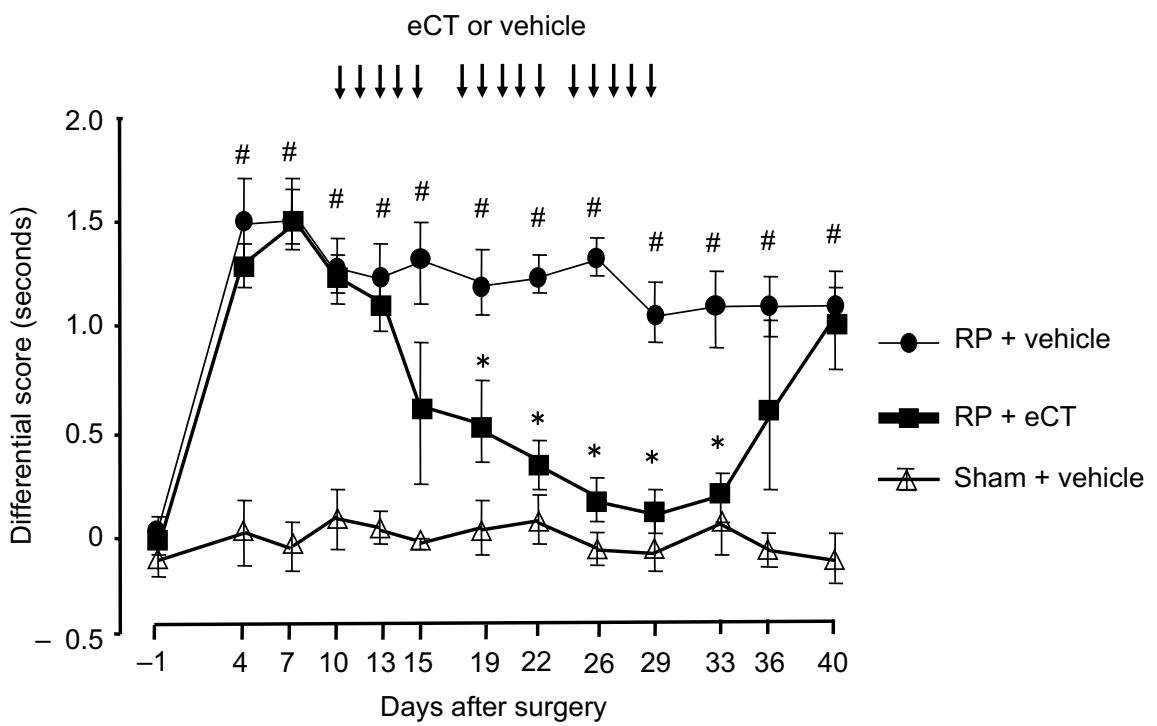

Figure I Time course for mechanical and thermal hyperalgesia.

Notes: (A) Mechanical hyperalgesia was evaluated 30 times as the frequency of withdrawal in response to mechanical stimulation of $3.8 \mathrm{~g}$ von Frey filament applied to the middle area between the foot pads on the plantar surface of the right and left hind paws. Mechanical withdrawal frequencies for each rat are expressed as the number of responses from the uninjured side, subtracted from the number of responses from the injured side. Compared with sham rats, rats with RP exhibited significantly more intense mechanical hyperalgesic reactions starting on postoperative day 4 and thereafter. Furthermore, hyperalgesic reactions decreased gradually with eCT administration. On day 5 after starting administration, hyperalgesia improved significantly in these rats compared with those that received the vehicle. However, they exhibited hyperalgesic reactions again 7 days after completing eCT administration. (B) Thermal hyperalgesia was evaluated using the differential score. This score for each rat was the thermal withdrawal latency of the injured side subtracted from the thermal withdrawal latency of the uninjured side. Withdrawal latency was defined as the time from the onset of radiant heat to the withdrawal of the tested foot. Mean withdrawal latency was calculated from the last four measurements. The differential score was significantly higher in the RP + vehicle group than in the sham + vehicle group from day 4 and thereafter. Hyperalgesia to a thermal stimulus had improved significantly 9 days after starting eCT administration, but reappeared 7 days after completing the administration. Values presented as mean $\pm S E M$. ${ }^{*}<<0.05$ compared to sham + vehicle or preoperation; $* P<0.05$ compared to RP + vehicle.

Abbreviations: RP, radicular pain; eCT, elcatonin.

median eminence, area postrema, and lamina terminals. ${ }^{29}$ It is possible that calcitonin exerts its analgesic actions through interactions with the central nervous system.

The hyperexcitation of the DRG is an important element in the occurrence of hyperalgesia. ${ }^{7,30,31}$ The excessive excitability of the DRG is transmitted to secondary afferent neurons at the spinal dorsal horn, which may induce central sensitization. As for voltage-dependent sodium channels expressed in the DRG, seven subtypes have been cloned. In this study, no significant differences were observed in 


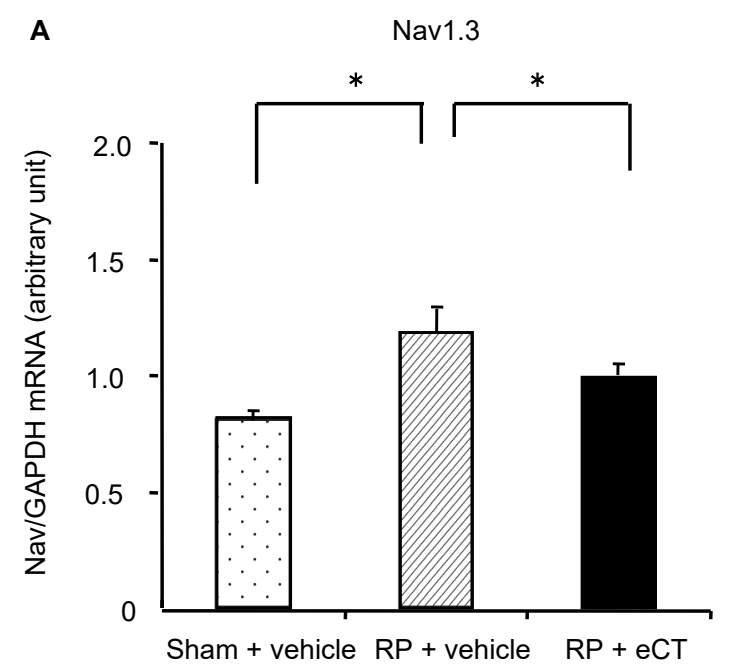

$\mathrm{Nav} 1.6$
$\mathrm{~ns}$

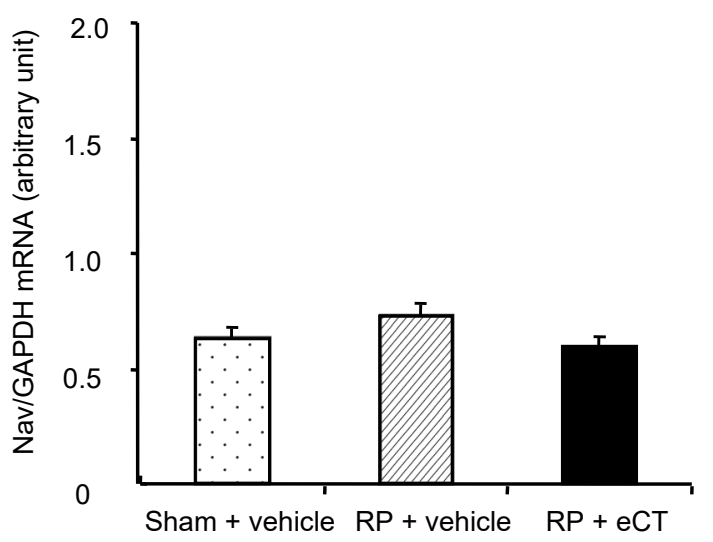

C

Nav 1.8

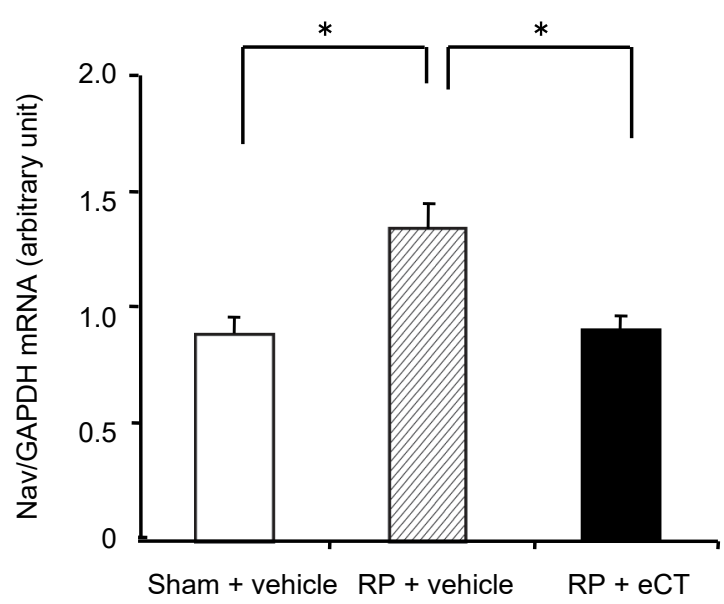

D

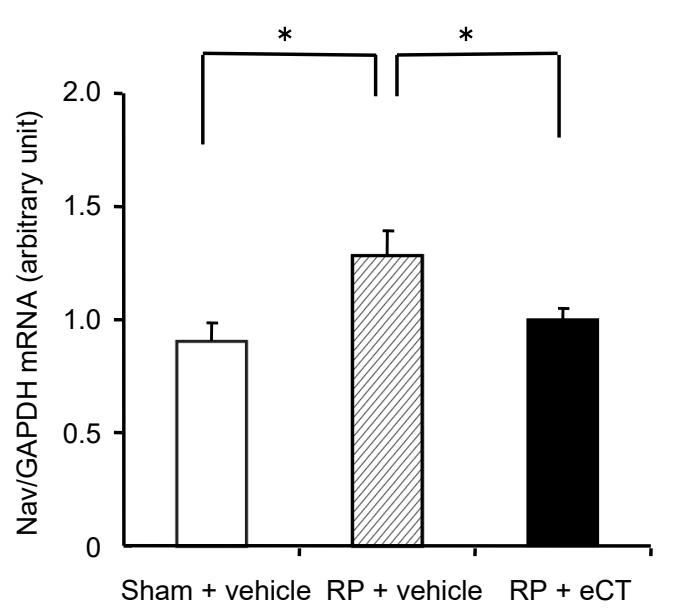

Figure 2 Changes in mRNA-expression levels of voltage-dependent TTX-sensitive and TTX-resistant sodium channels in the dorsal root ganglion.

Notes: Sodium-channel mRNA-expression levels were normalized to those of GAPDH and then compared among the RP + eCT, RP + vehicle, and sham + vehicle groups using relative values to the mean value of the sham group. (A) mRNA-expression levels of $\mathrm{Na}_{\mathrm{v}} 1.3$, values for the sham + vehicle and $\mathrm{RP}+$ vehicle groups were $0.82 \pm 0.04$ and I.19 \pm 0.09 , respectively; therefore, expression increased significantly in the latter group $(P<0.05)$. In the RP + eCT group, the expression level was $0.98 \pm 0.04$, indicating that expression levels of $\mathrm{Na}_{\mathrm{v}} \mathrm{l} .3$ improved to the same level as those of the sham group. (B) No significant differences were observed in expression levels of $\mathrm{Na}_{\mathrm{v}} \mathrm{I} .6$ among the sham + vehicle $(0.62 \pm 0.03), \mathrm{RP}+$ vehicle $(0.7 \mathrm{I} \pm 0.06)$, or $\mathrm{RP}+\mathrm{eCT}(0.59 \pm 0.04)$ groups. $(\mathbf{C}$ and $\mathbf{D}) \mathrm{mRNA}$-expression levels of $\mathrm{Na}_{\mathrm{v}} \mathrm{l} .8$ and $\mathrm{Na} \mathrm{v}_{\mathrm{v}} \mathrm{I} .9$ were $0.92 \pm 0.07$ and $0.92 \pm 0.08$ in the sham + vehicle group and $1.37 \pm 0.10$ and $1.26 \pm 0.10$ in the RP + vehicle group, respectively; therefore, levels increased significantly in the latter group $(P<0.05)$. Furthermore, levels were $0.94 \pm 0.05$ and $0.99 \pm 0.06$ in the RP $+\mathrm{eCT}$ group, respectively, indicating that mRNA-expression levels of $\mathrm{Na}_{\mathrm{v}} \mathrm{I} .8$ and $\mathrm{Na}_{\mathrm{v}} \mathrm{l} .9$ improved to the same level as those in the sham group. Values presented as mean \pm SEM. $* P<0.05$ compared RP + vehicle.

Abbreviations: eCT, elcatonin; RP, radicular pain; TTX, tetrodotoxin.

mRNA-expression levels of $\mathrm{Na}_{\mathrm{v}} 1.6$ among the three groups. On the other hand, mRNA-expression levels of $\mathrm{Na}_{\mathrm{v}} 1.3$, $\mathrm{Na}_{\mathrm{v}} 1.8$, and $\mathrm{Na}_{\mathrm{v}} 1.9$ increased in rats with radicular pain. $\mathrm{Na}_{\mathrm{v}} 1.8$ and $\mathrm{Na}_{\mathrm{v}} 1.9$, which are TTX-resistant sodium channels, are specifically expressed in small nociceptive neurons and believed to have important roles in the propagation of nociceptive information and expression of pathological pain. ${ }^{32,33}$ Furthermore, the expression of $\mathrm{Na}_{\mathrm{v}} 1.3$, which is a TTX-sensitive sodium channel, may be induced by nerve damage to generate abnormal action potentials. ${ }^{34}$ In the present study, in rats with radicular pain, the mRNAexpression levels of these voltage-dependent sodium channels increased. Watanabe et $\mathrm{al}^{35}$ reported the expression of $\mathrm{Na}_{\mathrm{v}} 1.8$ and $\mathrm{Na}_{\mathrm{v}} 1.9$ in the DRG increased by herniated nucleus pulposus following disk puncture. We assumed that radicular pain symptoms, observed in patients with lumbar spinal canal stenosis or lumbar disk herniation, are caused by changes in sodium-channel expression and abnormal sodium currents occurring in nociceptive neurons. Further analysis of the participation of each $\mathrm{Na}_{\mathrm{v}}$ subunit in voltage-activated 
sodium currents may lead to enhanced understanding of the alleviation of analgesic effects on radicular pain.

In the present study, after repeated calcitonin administration, mRNA-expression levels of these sodium channels improved to the same levels as those in the sham group, which suggested that calcitonin's action on the DRG may have played a role in normalizing the mechanism of pain transmission, particularly centered on $\mathrm{C}$ fibers. Ito et $\mathrm{al}^{21}$ reported that transcription of $\mathrm{Na}_{\mathrm{v}} 1.3$ increased and transcription of $\mathrm{Na}_{\mathrm{v}} 1.8$ and $\mathrm{Na}_{\mathrm{v}} 1.9$ decreased on the DRG in CCI rats. Further, they found that subcutaneous administration of eCT ( $15 \mathrm{U} / \mathrm{kg} /$ day) five times a week, from 11 to 27 days postsurgery, significantly restored the CCI-induced changes in the mRNA-expression levels of $\mathrm{Na}_{\mathrm{v}} 1.3, \mathrm{Na}_{\mathrm{v}} 1.8$, and $\mathrm{Na}_{\mathrm{v}} 1.9$. Moreover, repeated administration of calcitonin normalized the gene expression of sodium channels in CCI rats.

The target site of calcitonin's direct action remains to be identified. Mystakidou et $\mathrm{al}^{36}$ reported that calcitonin induces the secretion of blood $\beta$-endorphins, which has an analgesic effect. The serotonergic system is known to be involved in this analgesic effect. ${ }^{37,38}$ Ito et $\mathrm{al}^{39}$ reported that calcitonin interacts with serotonin receptors on $\mathrm{C}$-fiber termini to increase the number of serotonin receptors in the substantia gelatinosa of the dorsal horn in ovariectomized rats. They suggested that after nerve injury, it is important to reestablish the number of serotonin receptors so that the serotonin neurons that extend from the brain stem to the superficial dorsal horn can exert their pain-reducing action and provide hyperalgesia relief.

With regard to the expression of voltage-dependent sodium channels in the DRG, calcitonin can be presumed to act directly on the DRG or via calcitonin receptors or neurotrophic factors, such as the nerve growth factor or the glial cell line-derived neurotrophic factor. Further studies will be necessary to determine the site of the analgesic action of calcitonin, the pathway for intracellular transmission of information, and the mechanism of analgesic action of calcitonin in radicular pain.

\section{Conclusion}

Calcitonin has been used clinically as an analgesic agent for various pain-inducing diseases. The present preclinical study demonstrated that eCT was effective in male rats with radicular pain. In future, it is necessary to elucidate the true utility of calcitonin via clinical studies. Although calcitonin has known side effects, such as rash, facial flush, nausea, and vomiting, no serious side effects have been reported thus far. Therefore, calcitonin may be a preferred therapeutic option for elderly patients or those requiring long-term treatment.
Preclinical and clinical studies should be continued to clarify the mechanism of action of calcitonin in analgesia, identify diseases that have a favorable response to it, and specify the dose and period of administration for effective treatment.

\section{Acknowledgments}

The authors thank Akitoshi Ito (Asahi Kasei Pharma Co Ltd, Shizuoka, Japan) for his technical support with the RT-PCR procedures. This study was partially funded by Asahi Kasei Pharma Corporation.

\section{Disclosure}

The authors report no conflicts of interest in this work.

\section{References}

1. Bennett GJ, Xie YK. A peripheral mononeuropathy in rat that produces disorders of pain sensation like those seen in man. Pain. 1988;33(1):87-107.

2. Kim SH, Chung JMHo Kim S, Chung JM. An experimental model for peripheral neuropathy produced by segmental spinal nerve ligation in the rat. Pain. 1992;50(3):355-363.

3. Kawakami M, Weinstein JN, Spratt KF, et al. Experimental lumbar radiculopathy. Immunohistochemical and quantitative demonstrations of pain induced by lumbar nerve root irritation of the rat. Spine (Phila Pa 1976). 1994;19(16):1780-1794.

4. Kirita T, Takebayashi T, Mizuno S, et al. Electrophysiologic changes in dorsal root ganglion neurons and behavioral changes in a lumbar radiculopathy model. Spine (Phila Pa 1976). 2007;32(2):E65-E72.

5. Liu M, Wood JN. The roles of sodium channels in nociception: implications for mechanisms of neuropathic pain. Pain Med. 2011;12(Suppl 3):S93-S99.

6. Goldin AL, Barchi RL, Caldwell JH, et al. Nomenclature of voltagegated sodium channels. Neuron. 2000;28(2):365-368.

7. Black JA, Dib-Hajj S, McNabola K, et al. Spinal sensory neurons express multiple sodium channel alpha-subunit mRNAs. Brain Res Mol Brain Res. 1996;43(1-2):117-131.

8. Hirakawa R, El-Bizri N, Shryock JC, Belardinelli L, Rajamani S. Block of $\mathrm{Na}^{+}$currents and suppression of action potentials in embryonic rat dorsal root ganglion neurons by ranolazine. Neuropharmacology. 2012;62(7):2251-2260.

9. Copp DH, Cheney B. Calcitonin-a hormone from the parathyroid which lowers the calcium-level of the blood. Nature. 1962;193(4813):381-382.

10. Knopp JA, Diner BM, Blitz M, Lyritis GP, Rowe BH. Calcitonin for treating acute pain of osteoporotic vertebral compression fractures: a systematic review of randomized, controlled trials. Osteoporos Int. 2005;16(10):1281-1290.

11. Pun KK, Chan LW. Analgesic effect of intranasal salmon calcitonin in the treatment of osteoporotic vertebral fractures. Clin Therap. 1989;11:205-209.

12. Yoh K, Tanaka K, Ishikawa A, et al. Health-related quality of life (HRQOL) in Japanese osteoporotic patients and its improvement by elcatonin treatment. J Bone Miner Metab. 2005;23(2):167-173.

13. Endo N, Fujino K, Doi T, et al. Effect of elcatonin versus nonsteroidal anti-inflammatory medications for acute back pain in patients with osteoporotic vertebral fracture: a multiclinic randomized controlled trial. J Bone Miner Metab. 2017;35(4):375-384.

14. Quatraro A, Minei A, de Rosa N, Giugliano D. Calcitonin in painful diabetic neuropathy. Lancet. 1992;339(8795):746-747.

15. Perez RS, Kwakkel G, Zuurmond WW, de Lange JJ. Treatment of reflex sympathetic dystrophy (CRPS type 1): a research synthesis of 21 randomized clinical trials. J Pain Symptom Manage. 2001;21(6):511-526. 
16. Sawada M, Ichinose M, Ishikawa S, Sasayama Y. Calcitonin induces a decreased $\mathrm{Na}^{+}$conductance in identified neurons of Aplysia. J Neurosci Res. 1993;36(2):200-208.

17. Zimmermann M. Ethical guidelines for investigations of experimental pain in conscious animals. Pain. 1983;16(2):109-110.

18. Miyakawa T, Terashima Y, Takebayashi T, et al. Transient receptor potential Ankyrin 1 in spinal cord dorsal horn is involved in neuropathic pain in nerve root constriction rats. Mol Pain. 2014;10:58.

19. Mizuno S, Takebayashi T, Kirita T, Tanimoto K, Tohse N, Yamashita $\mathrm{T}$. The effects of the sympathetic nerves on lumbar radicular pain: a behavioural and immunohistochemical study. J Bone Joint Surg Br. 2007;89(12):1666-1672.

20. Terashima Y, Kawamata M, Takebayashi T, Tanaka S, Tanimoto K, Yamashita T. Changes in synaptic transmission of substantia gelatinosa neurons in a rat model of lumbar radicular pain revealed by in vivo patch-clamp recording. Pain. 2011;152(5):1024-1032.

21. Ito A, Takeda M, Yoshimura T, et al. Anti-hyperalgesic effects of calcitonin on neuropathic pain interacting with its peripheral receptors. $\mathrm{Mol}$ Pain. 2012;8:42.

22. Sleeper AA, Cummins TR, Dib-Hajj SD, et al. Changes in expression of two tetrodotoxin-resistant sodium channels and their currents in dorsal root ganglion neurons after sciatic nerve injury but not rhizotomy. J Neurosci. 2000;20(19):7279-7289.

23. Gibson UE, Heid CA, Williams PM. A novel method for real time quantitative RT-PCR. Genome Res. 1996;6(10):995-1001.

24. Heid CA, Stevens J, Livak KJ, Williams PM. Real time quantitative PCR. Genome Res. 1996;6(10):986-994.

25. Umeno H, Nagasawa T, Yamazaki N, Kuraishi Y. Antinociceptive effects of repeated systemic injections of calcitonin in formalin-induced hyperalgesic rats. Pharmacol Biochem Behav. 1996;55(1):151-156.

26. Aoki M, Mori A, Nakahara T, Sakamoto K, Ishii K. Effect of synthetic eel calcitonin, elcatonin, on cold and mechanical allodynia induced by oxaliplatin and paclitaxel in rats. Eur J Pharmacol. 2012;696(1-3):62-69.

27. Shibata K. Ovariectomy-induced hyperalgesia and antinociceptive effect of elcatonin, a synthetic eel calcitonin. Pharmacol Biochem Behav. 1998;60(2):371-376.

28. Ito A, Yoshimura M. Mechanisms of the analgesic effect of calcitonin on chronic pain by alteration of receptor or channel expression. Mol Pain. 2017; 13:1-11.

29. van Houten M, Rizzo AJ, Goltzman D, Posner BI. Brain receptors for blood-borne calcitonin in rats: circumventricular localization and vasopressin-resistant deficiency in hereditary diabetes insipidus. Endocrinology. 1982;111(5):1704-1710.
30. Abdulla FA, Smith PA. Axotomy- and autotomy-induced changes in the excitability of rat dorsal root ganglion neurons. J Neurophysiol. 2001;85(2):630-643.

31. Song XJ, Vizcarra C, Xu DS, Rupert RL, Wong ZN, Ds X. Hyperalgesia and neural excitability following injuries to central and peripheral branches of axons and somata of dorsal root ganglion neurons. $J \mathrm{Neu}$ rophysiol. 2003;89(4):2185-2193.

32. Djouhri L, Fang X, Okuse K, Wood JN, Berry CM, Lawson SN. The TTX-resistant sodium channel $\mathrm{Na}_{\mathrm{v}} 1.8$ (SNS/PN3): expression and correlation with membrane properties in rat nociceptive primary afferent neurons. J Physiol. 2003;550(Pt 3):739-752.

33. Fang X, Djouhri L, Black JA, Dib-Hajj SD, Waxman SG, Lawson SN. The presence and role of the tetrodotoxin-resistant sodium channel $\mathrm{Na}_{\mathrm{v}} 1.9(\mathrm{NaN})$ in nociceptive primary afferent neurons. $J$ Neurosci. 2002;22(17):7425-7433.

34. Waxman SG, Kocsis JD, Black JA. Type III sodium channel mRNA is expressed in embryonic but not adult spinal sensory neurons, and is reexpressed following axotomy. J Neurophysiol. 1994;72(1): $466-470$.

35. Watanabe K, Larsson K, Rydevik B, Konno S, Nordborg C, Olmarker K. Increase of sodium channels (nav 1.8 and nav 1.9) in rat dorsal root ganglion neurons exposed to autologous nucleus pulposus. Open Orthop J. 2014;8(1):69-73.

36. Mystakidou K, Befon S, Hondros K, Kouskouni E, Vlahos L. Continuous subcutaneous administration of high-dose salmon calcitonin in bone metastasis: pain control and beta-endorphin plasma levels. J Pain Symptom Manage. 1999;18(5):323-330.

37. Hirakawa R, El-Bizri N, Shryock JC, Belardinelli L, Rajamani S. Block of $\mathrm{Na}^{+}$currents and suppression of action potentials in embryonic rat dorsal root ganglion neurons by ranolazine. Neuropharmacology. 2012;62(7):2251-2260.

38. Colado MI, Ormazabal MJ, Goicoechea C, Lopez F, Alfaro MJ, Martin MI. Involvement of central serotonergic pathways in analgesia elicited by salmon calcitonin in the mouse. Eur J Pharmacol. 1994;252(3):291-297.

39. Ito A, Kumamoto E, Takeda M, Shibata K, Sagai H, Yoshimura M. Mechanisms for ovariectomy-induced hyperalgesia and its relief by calcitonin: participation of 5-HT1A-like receptor on C-afferent terminals in substantia gelatinosa of the rat spinal cord. J Neurosci. 2000;20(16): 6302-6308.
Journal of Pain Research

\section{Publish your work in this journal}

The Journal of Pain Research is an international, peer reviewed, open access, online journal that welcomes laboratory and clinical findings in the fields of pain research and the prevention and management of pain. Original research, reviews, symposium reports, hypothesis formation and commentaries are all considered for publication.

\section{Dovepress}

The manuscript management system is completely online and includes a very quick and fair peer-review system, which is all easy to use. Visit http://www.dovepress.com/testimonials.php to read real quotes from published authors. 